\title{
Performance Investigation of 112 Gb/s Hybrid Multiband CAP/QAM Schemes for Short Reach Optical Communication Systems
}

\author{
${ }^{1}$ Majidah H. Majeed and ${ }^{2}$ Raad S. Fyath \\ ${ }^{1}$ Department of Electrical Engineering, College of Engineering, University of Baghdad, Baghdad, Iraq, \\ ${ }^{2}$ Department of Computer Engineering, College of Engineering, University of Al-Nahrain, Baghdad, Iraq \\ majidahmajeed@gmail.com; rsfyath@yahoo.com
}

\begin{abstract}
The transmission performance of $112 \mathrm{~Gb} / \mathrm{s}$ hybrid multiband (HMB) carrier-less amplitude and phase (CAP)/quadrature amplitude modulation (QAM) system over a single mode fiber (SMF) is investigated. Analog squared root-raised cosine (SRRC) orthogonal shaping filters are used to implement the CAP signal that is used to modulate the $1550 \mathrm{~nm}$ (or $1310 \mathrm{~nm}$ ) continuous wave (CW) laser using Mach-Zehnder modulator. Simulation of HMB CAP-M/QAM-M schemes with $M=16,32$, and 64 is performed and the results are compared with that of the corresponding $112 \mathrm{~Gb} / \mathrm{s}$ single-band of the same scheme. The results show that increasing the roll-off factor $r$ will improve the bit error rate (BER) performance of the system. The optical power required to achieve a BER of $10^{-3}$ for CAP-16/QAM-16 system reduces by 0.75 and $1.88 \mathrm{dBm}$ for four-subband and single-band schemes, respectively, when $r$ increases from 0 to 0.4 . While the improvement in the laser transmitted optical power for 4-subband and single-band CAP32/QAM-32 schemes is 0.5 and $0.45 \mathrm{dBm}$, respectively.
\end{abstract}

Keywords: Multiband CAP; CAP/QAM system; $112 \mathrm{~Gb} / \mathrm{s}$ system; roll-off factor.

\section{Introduction}

Day by a day, the objective toward getting services of the highest data rate, such as video and audio messages, exchange of data, TV application and other social networking has been on the demand. The power budget and the power dissipation of advanced modulation formats such as $100 \mathrm{~Gb} / \mathrm{s}$ CAP-16/64 and quadrature amplitude modulation (QAM)-orthogonal frequency division multiplexing (OFDM) systems were evaluated and compared for single channel and two coarse wavelength division multiplexing (CWDM) channel cases [1]. It was found that single channel CAP-16 and 16-QAM-OFDM links can successfully support transmission over $5 \mathrm{~km} \mathrm{SMF}$, with power dissipation 2 times that of $4 \times 25 \mathrm{~Gb} / \mathrm{s}$ NRZ system. The number of components required for short reaches optical communication modules at $100 \mathrm{~Gb} / \mathrm{s}$ are reduced using advanced modulation formats such as, pulse amplitude modulation (PAM) and CAP [2]. For longer transmission and data rate beyond $100 \mathrm{~Gb} / \mathrm{s}$, multicarrier modulation based on discrete multitone modulation and /or offset OFDM over $20 \mathrm{~km} \mathrm{SMF}$ and directly modulated laser (DML) was achieved [2].The investigation and simulation of the effect of digital filters in CAP modulation systems 
was reported in [3] and the results reveal that the appropriate number of taps of the shaping and matched filters will have considerable influence on the BER performance of transmission systems. Numerical simulation of multiband CAP for beyond $100 \mathrm{~Gb} / \mathrm{s}$ short range optical data links was performed [4] and the results show that significant improvements for bandwidth and dispersion limited channels. Further, the complexity of the CAP transceivers in terms of hardware requirements is reduced regardless using digital or analog implementation by either reducing or the sampling frequency or the bandwidth requirements of the analog filters. Single laser100 Gb Ethernet link was investigated using HMB CAP$M / Q A M-M$ with $M=16,32$, and 64 transceivers [5] and the results show that the proposed scheme has low sensitivity to DML nonlinearities. It was also found that QAM receivers are equivalent to phase compensated CAP receivers on aspect of jitter tolerance and the use of QAM receivers significantly lowers the system sensitivity to timing jitter. Furthermore, there is an optimum band count for each scheme corresponding to maximum optical margin. All the above references present the results for a fixed value of the CAP filters roll-off factor.

In this paper, the transmission of CAP-M/QAM-M, with $M=16,32$, and 64is investigated to show how the performance of the system is affected by the roll-off factor $r$ of the SRRC shaping and matched filters. The CAP signal is generated using orthogonal analog I and Q SRRC filters.

This paper is organized as follows. Section 2 presents the mathematical framework required to analyze SRRC filter-based CAP/QAM transceiver. The advantages of the roll-off factor and the squared-root raised cosine filter are also explained in this section. The operation of HMBCAP/QAM architecture, which includes the analysis of the simulated system in detailed and gives the parameters values of the simulated system, are introduced in section 3 . The results obtained from the simulation of the system are summarized in section 4. Finally, the conclusions drawn from this work is presented in section 5.

\section{Concepts of CAP/QAM}

\subsection{CAP Modulation}

The CAP modulation is one of the advanced modulation formats which can be implemented in a digital or analog form. CAP modulation is a two-dimensional (2-D) or multidimensional passband transmission signal format which looks like QAM modulation but the CAP modulation does not need local oscillator (LO) and mixer. The digital implementation of CAP-16 modulation is performed by encoding the input binary data using two PAM-4 mappers each has four-level amplitude as shown in Figure1. The mappers generate the in-phase part $(X(i))$ and the quadrature part $(Z(i))$ of the symbols, respectively [2]. The inphase $X(i)$ and quadrature $Z(i)$ symbols are applied to the input of SRRC shaping filters. By combining the filters' outputs, the multilevel CAP signal is obtained.

$$
\begin{gathered}
\mathrm{S}(\mathrm{t})=\sum_{i} X(i) R(t-i T)-Z(i) \hat{\mathrm{R}}(t-i T) \\
\mathrm{R}(\mathrm{t})=\mathrm{g}(\mathrm{t}) \cos \left(2 \pi \mathrm{f}_{\mathrm{c}} \mathrm{t}\right) \\
\hat{\mathrm{R}}(\mathrm{t})=\mathrm{g}(\mathrm{t}) \sin \left(2 \pi \mathrm{f}_{\mathrm{c}} \mathrm{t}\right)
\end{gathered}
$$




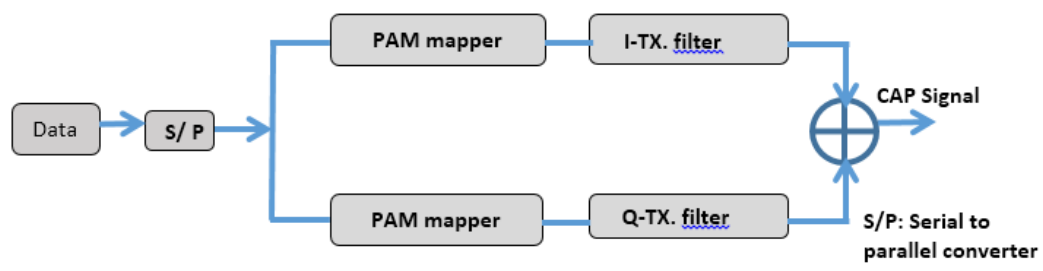

Figure. 1 Block diagram of CAP signal generation.

where $g(t)$ is the impulse response of SRRC filter and $f_{c}$ is the center frequency of the subband in the CAP/QAM system. The two filters $R(t)$ and $\hat{R}(t)$ form a so named Hilbert pair. A Hilbert pair is two signals of the same magnitude response but with phase responses shifted by $(\pi / 2)$ radian. Equation (2) indicates that the impulse response of I and $Q$ shaping filters is obtained from time multiplication the SRRC output with cosine and sine waveforms, respectively.

The CAP modulation has many advantages, among them are

i. It increases the spectral efficiency by increasing the order of modulation and then increasing the data rate for a given transmitted bandwidth [6].

ii. Since CAP modulation is of high bandwidth efficiency, low implementation costsand support modulation more than 2-dimensional format.CAP has been widely used in asynchronous digital subscriber link and asynchronous transfer mode local area network $[2,7]$.

iii. iii-It neither requires discrete Fourier transform utilized in OFDM signal generation and demodulation, nor needs complex mixer and local oscillator as the QAM used.

iv. It needs simpler digital signal processing(DSP) implementation and does not require analog-todigital or digital-to-analog convertors.

v. It is of excellent performance using low cost and limited bandwidth DML and vertical cavity surface-emitting lasers.

vi. It allows high data rate.

vii. CAP receivers have low tolerance to high frequency jitter [5].

viii. viii-In multiband, the bandwidth is divided into smaller subbands, so CAP lowers the peak-toaverage power ratio (PAPR) [4].

\subsection{Squared Root-Raised Cosine Filter}

The design of the shaping filters in the CAP transmitter and the receiver are based on Nyquist criterion in order to remove the inter symbol interference (ISI) between the adjacent symbols. If the lowpass transmitted signal is band limited to (W) Hertz, it can be viewed as sending a minimum of (2W) independent symbols per second through a channel represented by an ideal lowpass filter of bandwidth (W). If the $i^{\text {th }}$ impulse of amplitude $a_{i}$ is transmitted through the channel at time $t=i T=(i / 2 W), T$ is the sampling time, the output of the channel is given by [8] 


$$
y_{i}(t)=a_{i} \operatorname{sinc}\left[2 W\left(t-\frac{i}{2 W}\right)\right]
$$

For a sequence of impulses spaced byT $=1 /(2 \mathrm{~W})$, the channel

$$
\mathrm{y}(\mathrm{t})=\sum_{i} y_{\mathrm{i}}(t)=\sum_{i} a_{\mathrm{i}} \operatorname{sinc}[2 W(t-i / 2 W)]
$$

If the channel output is sampled at time $t_{m}=m / 2 W$, the sample value is $a_{m}$ because the sinc function equals either 1 when $m=i$ or zero for $m \neq i$. Then, the $m^{\text {th }}$ sample value at the output of the channel is not affected by the last or the next sample values which ensures zero ISI.

There are band-limited waveforms other than $\operatorname{sinc}(2 \mathrm{Wt})$ that have the property of zero ISI but their zero crossings are spaced by $T=1 / 2 \mathrm{~W}$ seconds. These waveform have raised cosine spectrum. The pulse shaping, ISI, and the bandwidth are very important parameters in the design of telecommunication systems transmitting high data rates over limited-bandwidth channel The implementation of the required raised cosine response is obtained by splitting the filter into two parts, each one called root-raised cosine filter whose impulse response is given by

$$
\mathrm{h}(\mathrm{t})=\frac{\sin \pi t \backslash T}{\pi t \backslash T} \frac{\cos \pi r t \backslash T}{1-(2 r t \backslash T)^{2}}
$$

where $T$ is the sampling interval and $r$ is the filter roll-off factor. The term $\frac{\sin \pi t \backslash T}{\pi t \backslash T}$ in equation (5) ensures that the impulse response has zero crossing and it describes an ideal lowpass filter (LPF). The second term $\frac{\cos (\pi r t \backslash T)}{1-(2 r t \backslash T)^{\wedge} 2}$ in equation (5) decays quickly with time, hence reduces the response tails and then reducing the impact of jitter.

The frequency response of the raised cosine filter is

$$
\mathrm{H}(\mathrm{f})=\left\{\begin{array}{cc}
\mathrm{T} & 0 \leq|f| \leq \frac{1-r}{2 T} \\
\sqrt{\left(\frac{T}{2}\left\{1+\cos \left[\frac{\pi T}{r}\left(|f|-\frac{1-r}{2 T}\right)\right]\right\}\right)} & \frac{1-r}{2 T} \leq|f| \leq \frac{1+r}{2 T} \\
0 & |f|>\frac{1+r}{2 T}
\end{array}\right.
$$

To get the squared root-raised cosine (SRRC) response at the transmitter and the receiver, the square root of the frequency response of the raised cosine filter is taken $[9,10]$

$$
\mathrm{H}_{\mathrm{SRRC}}(\mathrm{f})=\sqrt{H(f)}
$$

and the impulse response of SRRC is

$$
\mathrm{h}(\mathrm{t})=\frac{2 r}{\pi \sqrt{T}} \frac{\cos [(1+r) \pi t \backslash T]}{1-(4 r t \backslash T)^{\wedge} 2}+\frac{2 r}{\pi \sqrt{T}} \frac{\frac{\sin [(1-r) \pi t \backslash T]}{4 r t \backslash T}}{1-(4 r t \backslash T)^{\wedge} 2}
$$

The SRRC response theoretically has infinite number of taps so it has infinite attenuation in the stop band. Practically the length should be truncated to finite value. If the number of samples is reduced, the stop band attenuation will be reduced [9].

The main advantages of the roll-off factor of the SRRC filter are [9] 
Majidah H. Majeed and Raad S. Fyath; Performance Investigation of $112 \mathrm{~Gb} / \mathrm{s}$ Hybrid Multiband CAP/QAM Schemes for Short Reach Optical Communication Systems, Transactions on Networks and Communications, Volume 4 No. 6, December (2016); pp: 10-32

i- $\quad$ Excess in the RF bandwidth of the CAP transmitted signal bandwidth

$$
\text { Bandwidth }=(1+r) \times \text { Symbol rate }
$$

As the roll-off factor increases, the bandwidth of the CAP signal increases and its frequency response becomes closer to the frequency response of the SRRC filter. If the roll-off factor equal to zero, then the raised cosine filter reduces to the ideal LPF having rectangular spectrum. As the roll off factor becomes larger, the eye opens up, the bandwidth will not be limited and the receiver design would be easier. Although, it is better to enlarge the roll-off factor, however, for bandwidth efficiency, the roll-off factor should be small.

ii- $\quad$ ii- The term $\frac{\sin (2 \pi t \backslash T)}{2 \pi t}$ (sinc pulse) in the impulse response of SRRC helps in extracting timing information of the signal, because it ensures that the function transition at integer multiples of the symbol rate. Thus the bandwidth will be varied from ( $0.5 \mathrm{Rs}$ to Rs), where Rs is the symbol rate, and will be greater than the Nyquist bandwidth by a factor of $(1+r)$.

iii- $\quad$ The shaping filter has an effect on the PAPR. PAPR of the RRC filters will increase with reducing excess bandwidth and increasing filter length.

\section{Operation of Multiband CAP/QAM System}

\subsection{System Analysis}

The block diagram of HMB CAP/QAM system is shown in Figure2. The performance of the system is determined by measuring the BER of each sub-band. The pseudo random binary sequence generator sequence (PRBS) produces $112 \mathrm{~Gb} / \mathrm{s}$ data which is split into four paths, each of $28 \mathrm{~Gb} / \mathrm{s}$ rate corresponding to one subband. The CAP signal is generated through many stages as shown in Figure 3. Each subband transmitter consists of two PAM-4 mappers to produce the in-phase (I) and quadrature components (Q) of the complex symbols of $7 \mathrm{Gbaud}$ and the waveform at each mapper is set as an input to the I and $\mathrm{Q}$ analog shaping filters. The overall K-band system needs $2 \mathrm{~K}$ passband filters of Hilbert pair form. The I and $Q$ filters are formed as SRRC filters whose impulse response is given in equation (8).

The choice of the center frequency should ensure orthogonally between power spectral densities of the subbands and this indicates that there is no overlap between any two adjacent subbands [5]. This means that the two I and $Q$ filters are orthogonal. By combining the output of $K$ subbands, the multiband CAP signal is generated as defined in equation (10).

$$
\mathrm{S}(\mathrm{t})=\sum_{k=1}^{K}\left[\sum_{i} X_{k, i} g(t-i T) \cos \omega_{k, c}(t-i T)-\sum_{i} Z_{k, i} g(t-i T) \cos \omega_{k, c}(t-i T)\right.
$$

$X_{k, i}$ and $Z_{k, i}$ are the I and Q parts of the PAM-4 symbols, respectively, that are input to $\mathrm{K}$ subbands, $\omega_{k, c}$ $=2 \pi \mathrm{f}_{k, c}$, and $\mathrm{f}_{k, c}$ is the center frequency of the $\mathrm{k}^{\text {th }}$ subband, and $g(t)$ is the impulse response of the SRRC filter.

The generated multiband CAP signal is used to modulate the $1550 \mathrm{~nm}$ or $1310 \mathrm{~nm} \mathrm{CW}$ laser through the Mach-Zehnder modulator (MZM). The output optical signal is launched through a SMF. The received signal is detected by a PIN photodiode (PD) and its output is split into $2 \mathrm{~K}$ parts to be demodulated using QAM 
demodulators. The I and Q outputs of the SRRC matched filters, $y_{A}(t)$ and $y_{B}(t)$, respectively, are given by [11]

$$
y_{A}(t)=y_{k, I}(t)+y_{k, I q}(t)
$$

where $y_{k, I}(t)$ is the in-phase or desired signal, $y_{k, I q}(t)$ is the signal from quadrature channel that interfered with the desired signal. Let $f(t)$ be the impulse response of matched filter at the receiver which has a conjugate relationship in frequency domain with the SRRC shaping filters at the transmitter $(f(t)=$ $g(-t))$. The I and Q impulse response of the matched filters are given, respectively, by

$$
\begin{gathered}
U_{k, c}(t)=g(-t) \cos \left(2 \pi f_{k, c} t\right) \\
\widetilde{U}_{k, c}(t)=g(-t) \sin \left(2 \pi f_{k, c} t\right) \\
y_{k, I}(t)=\sum_{k=1}^{K}\left[\sum_{i} X_{k i} g(t-i T) \cos \omega_{k, c}(t-i T)\right] \cos \left(\omega_{k, c} t+\theta\right) \otimes f(t) \\
y_{k, I}(t)=\sum_{k=1}^{K} 0.5 \sum_{i} X_{k, i} g(t-i T)\left\{\cos \left(\omega_{k, c}(2 t-i T)+\theta\right) \cos \left(\omega_{k, c} i T+\theta\right)\right\} \otimes f(t)
\end{gathered}
$$

$\theta$ is the time delay caused by the fiber link. The term $\cos \left(\omega_{k, c}(2 t-i T)+\theta\right)$ is discarded by the lowpass matched filter.

$$
\begin{gathered}
\left.y_{k, I}(t)=\sum_{k=1}^{K}\left\{0.5 \sum_{i} X_{k, i} g(t-i T) \cos \left(\omega_{k, c} i T+\theta\right)\right\} \otimes f(t)\right) \\
y_{I}(t)=\sum_{i} X_{i} h(t-i T) \cos \omega_{c} i T
\end{gathered}
$$

where $\mathrm{h}(\mathrm{t})=0.5 g(t) \otimes f(t)$ which is the Nyquist pulse.

The interference from the quadrature channel

$$
\begin{gathered}
y_{k, I q}(t)=\sum_{k=1}^{K}\left[-\sum_{i} Z_{k, i} g(t-i T) \sin \omega_{k, c}(t-i T)\right] \cos \left(\omega_{k, c} t+\theta\right) \otimes f(t) \\
y_{I q}(t)=\sum_{i} Z_{i} h(t-i T) \sin \omega_{c} i T \\
y_{A}(t)=\sum_{i} X_{i} h(t-i T) \cos \omega_{c} i T+\sum_{i} Z_{i} h(t-i T) \sin \omega_{c} i T
\end{gathered}
$$

The first term in equation (14) contains the desired transmitted signal from the $k$ channel and the second term is the cross channel interference from $Q$ channel.

The signal $y_{B}(t)$ can be found using the same steps followed to find $y_{A}(t)$. The result is

$$
y_{B}(t)=\sum_{i} Z_{i} h(t-i T) \cos \left(\omega_{c} i T\right)-\sum_{i} X_{i} h(t-i T) \sin \left(\omega_{c} i T\right)
$$




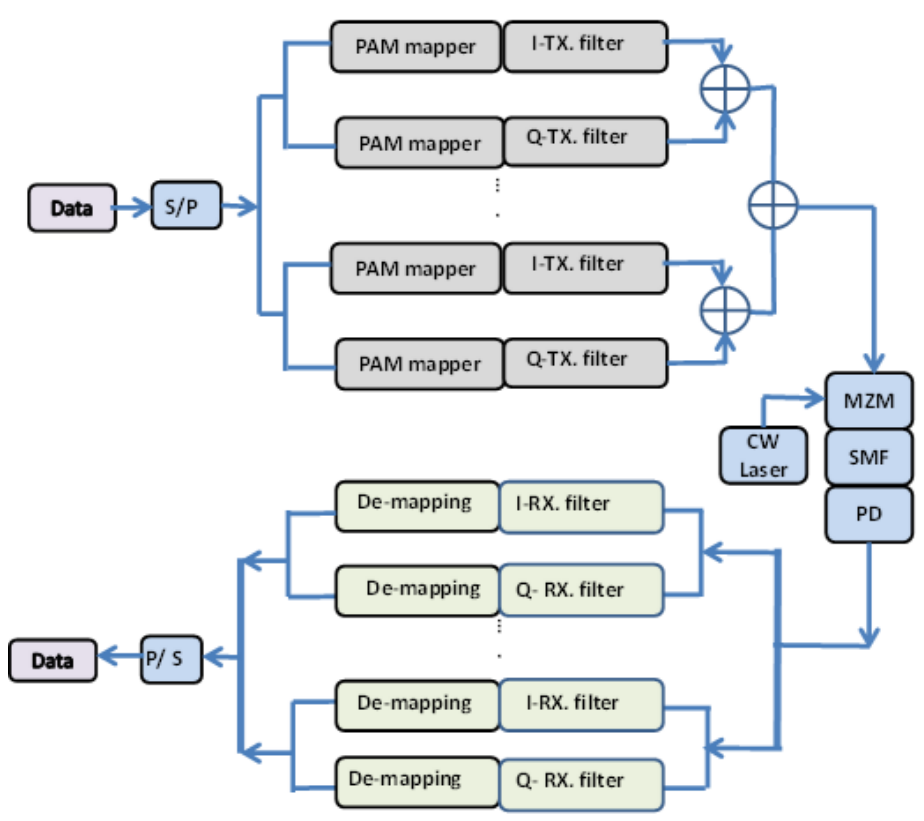

Figure. 2 Block diagram of HMB CAP/QAM system.

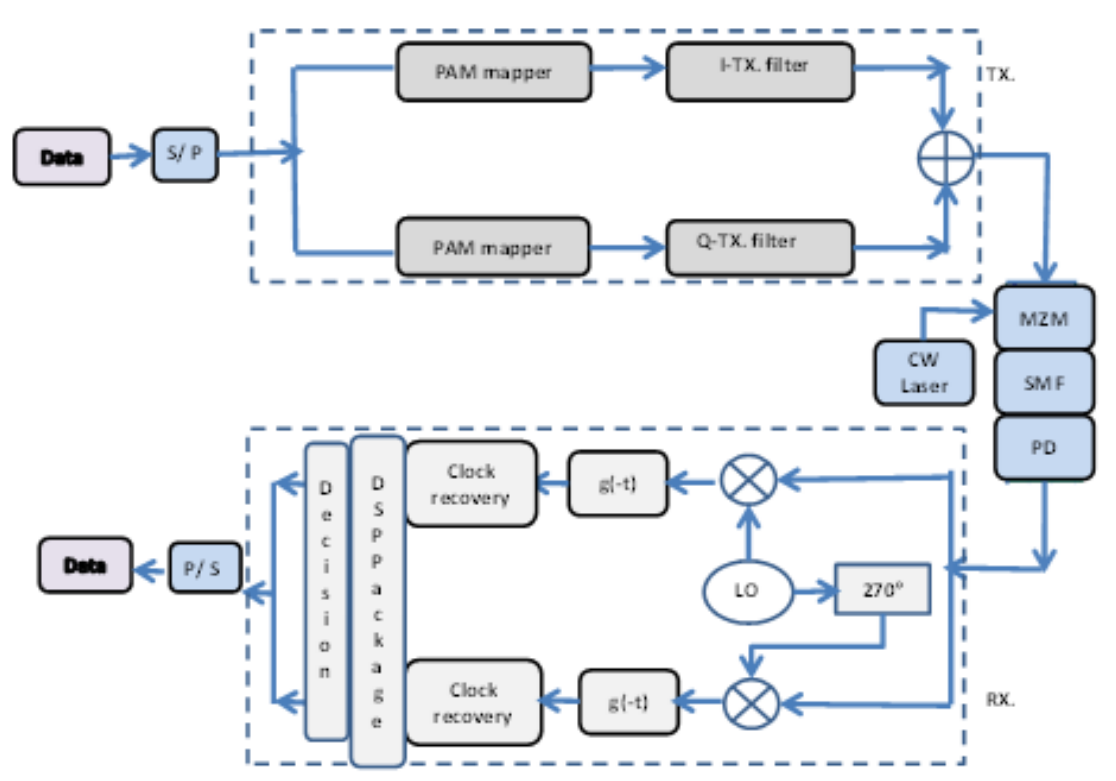

Figure. 3 Block diagram of single band CAP/QAM system.

The signals $y_{A}(t)$ and $y_{B}(t)$ are applied to the input port of clock recovery components to compensate the time delay between the signal at the reference port (SRRC shaping filters) and the received signals at the input port of the clock recovery components of I and $Q$ channels. These signals will be off-line processed using DSP package, which perform many important functions such as up-sampling, DC blocking and normalization. Other essential functions and algorithms are also achieved by this DSP package among them, resampling, IQ compensation, chromatic dispersion (CD) compensation that results through the propagation along the fiber link and compensated using digital filtering. 
The rotation of the signal constellation is corrected by the DSP package

$$
\begin{gathered}
\bar{X}=\operatorname{Re}\left\{\left[y_{A}(t)+j y_{B}(t)\right] \cdot e^{j\left(\omega_{k, c} \mathrm{iT}\right.}\right\} \\
\bar{X}=\sum_{i} X_{i} h(t-i T)
\end{gathered}
$$

And

$$
\begin{gathered}
\bar{Z}=\operatorname{Im}\left\{\left[y_{A}(t)+j y_{B}(t)\right] \cdot e^{j\left(\omega_{k, c} \mathrm{iT}\right.}\right\} \\
\bar{Z}=\sum_{i} Z_{i} h(t-i T)
\end{gathered}
$$

The decision device performs soft decision on the received symbols based on the threshold boundaries of 16-QAM signal constellation in order to find the optimum decision and correct any rotation prior to applying the soft decision.

Unless otherwise stated, the analysis of the system is taken for two cases back-to-back (B2B) and transmission of the optical signal over $1 \mathrm{~km}$ distance. In the second case, because of the dispersion in the fiber, laser line-width, and frequency offset, the received signal constellation is rotated due to the variation of the positions of the symbols in the I-Q plane. The symbols are returned back to their original positions as that in the transmitter through correlation operation performed using the decision device.

The final steps that should be performed are de-mapping the detected data to I and Q parts then the decoding the two signal parts to recover the original data using the QAM decoder.

The center frequency of the $\mathrm{K}$ subbands can be found, the first term of equation (5) which is $\frac{\sin \pi t \backslash T}{\pi t \backslash T}$ emphases that the impulse response has zero crossing, as that in the ideal low pass filter, where the bandwidth is defined as the distance from the origin to the first zero crossing. Then the cutoff frequency is defined by $\mathrm{f}_{\mathrm{c}}=0.5 \mathrm{f}_{\mathrm{s}}$.

The realizable bandwidth of raised cosine filter B is Nyquist bandwidth $\times(1+r)$

$$
\mathrm{B}=\mathrm{f}_{\mathrm{c}}=\frac{1}{2 \mathrm{~T}}(1+r)
$$

Here $\mathrm{f}_{\mathrm{c}}$ is the center frequency of the first subband of the system. For K-band system, the $\mathrm{k}^{\text {th }}$ center frequency is

$$
\mathrm{f}_{\mathrm{k}, \mathrm{c}}=\frac{1}{2 \mathrm{~T}}(1+r)(2 \mathrm{k}-1) \mathrm{k}=1,2,3, \ldots \mathrm{k}
$$

\subsection{Simulation Parameters Values}

The designed system of 112 Gb/s HMB CAP-16 system shown in Figure (2) is simulated using OptiSystem version 14.0. For $K$ subbands, the bit rate and the symbol rate for each subband is $(112 / \mathrm{K}) \mathrm{Gb} / \mathrm{s}$ and (112/ $\left.\log _{2} M\right)$ Gbaud, respectively, where $M=16,32$, or 64 . For example, for 4-subband scheme, the bit rate and the symbol rate for each subband is $28 \mathrm{~Gb} / \mathrm{s}$ and $7 \mathrm{Gbaud}$, respectively. The center frequencies of the subbands are calculated using equation (19) for $r=0.3$ and the results are summarized in Table 1.

The information data of rate $112 \mathrm{~Gb} / \mathrm{s}$ branch is split into four $28 \mathrm{~Gb} / \mathrm{s}$ subbands which are encoded to NRZ electrical pulses of rise time and fall time of 0.25 bit. The encoded bits are mapped to I and $Q$ parts of the complex symbols using two gray code PAM-4 mappers and the outputs are sent to the analog SRRC shaping filters. The output of $K$ subbands are combined in order to obtain the multiband CAP signal which is used to modulate the CW laser of $1550 \mathrm{~nm}$ or $1310 \mathrm{~nm}$ wavelength through MZM modulator. The 
Majidah H. Majeed and Raad S. Fyath; Performance Investigation of 112 Gb/s Hybrid Multiband CAP/QAM Schemes for Short Reach Optical Communication Systems, Transactions on Networks and Communications, Volume 4 No.

6, December (2016); pp: 10-32

transmitted optical power propagates through a SMF link and the received optical signal is directly detected by a PIN photodiode. The electrical signal is demodulated using QAM-16demodulator. The SRRC matched filters of same properties, that is used in the transmitter, receive the demodulated signal and the output of these filters are off-line processed using DSP package for QAM-16 of symbol rate equal to bit rate divided by4. The optimum decision of each received symbol is carried out by the decision component. Finally the 4 bits QAM decoder is used to get the recovered transmitted information data. Unless otherwise stated, the parameters of the simulated system are as given in Table 2.

Table 1. Center frequency of the Subbands of HMB CAP-16/QAM-16 scheme designed with r=0.3 SRRC filters.

\begin{tabular}{|c|c|c|c|}
\hline Subband Number & \multicolumn{3}{|c|}{ Center Frequencies (GHz) } \\
\hline & 4-Subband Scheme & 8-Subband Scheme & 16-Subband Scheme \\
\hline 1 & 4.55 & 2.275 & 1.1375 \\
\hline 2 & 13.65 & 6.825 & 3.4125 \\
\hline 3 & 22.75 & 11.375 & 5.6875 \\
\hline 4 & 31.85 & 15.925 & 7.9625 \\
\hline 5 & & 20.475 & 10.2375 \\
\hline 7 & & 25.025 & 12.5125 \\
\hline 8 & & 29.575 & 14.7875 \\
\hline 10 & & 34.125 & 17.0625 \\
\hline 11 & & & 19.3375 \\
\hline 12 & & & 21.6125 \\
\hline 13 & & & 23.8875 \\
\hline 14 & & & 26.1625 \\
\hline 15 & & & 28.4375 \\
\hline & & & 30.7125 \\
\hline & & & 32.9875 \\
\hline
\end{tabular}

Table 2. Parameters values of the simulated system.

\begin{tabular}{|c|c|c|}
\hline Component & Property & Value \\
\hline \multirow{3}{*}{ CW laser } & Linewidth & $50 \mathrm{MHz}$ \\
\hline & Wavelength & $1550 \mathrm{~nm}$ and $1310 \mathrm{~nm}$ \\
\hline & Power & $0 \mathrm{dBm}$ \\
\hline \multirow{4}{*}{ Optical fiber link } & Length & $1 \mathrm{~km}$ \\
\hline & Attenuation & $0.2 \mathrm{~dB} / \mathrm{km} @ 1550 \mathrm{~nm}$ \\
\hline & Dispersion & $\begin{array}{c}16.75 \mathrm{ps} / \mathrm{nm} / \mathrm{km} @ 1550 \mathrm{~nm} \\
0.01 \mathrm{ps} / \mathrm{nm} / \mathrm{km} @ 1310 \mathrm{~nm}\end{array}$ \\
\hline & Dispersion Slope & $\begin{array}{l}0.075 \mathrm{ps} / \mathrm{sqrt}(\mathrm{nm}) . \mathrm{km} @ 1550 \mathrm{~nm} \\
0.09 \mathrm{ps} / \mathrm{sqrt}(\mathrm{nm}) . \mathrm{km} @ 1310 \mathrm{~nm}\end{array}$ \\
\hline \multirow{3}{*}{ PIN PD } & Responsively & $1 \mathrm{~A} / \mathrm{W}$ \\
\hline & $\begin{array}{l}\text { Power spectral density } \\
\text { of the thermal noise }\end{array}$ & $331.92 \times \mathbf{1 0}^{-\mathbf{2 4}} \mathrm{W} / \mathrm{Hz}$ \\
\hline & Modulation bandwidth & Bit rate \\
\hline Receiver LPF & Cutoff frequency & $0.75 \times$ bit rate \\
\hline
\end{tabular}




\section{Simulation Results}

The performance of HMB CAP/QAM is investigated using OptiSystem version 14.0 simulator and the obtained results of the proposed system are given in the following subsections.

\subsection{Effect of Roll-off Factor}

\subsubsection{CAP-16/QAM-16}

CAP-16/QAM-16 is the first scheme that is investigated and the signal constellation diagrams are obtained at the transmitter at the output of shaping filters as shown in Figure 4 for $0 \mathrm{dBm} \mathrm{CW}$ laser transmitted optical power $\left(\mathrm{P}_{\mathrm{T}}\right)$ at $1550 \mathrm{~nm}$ wavelength. It is clear how the discriminating of the 16 symbols becomes better with increasing $r$.

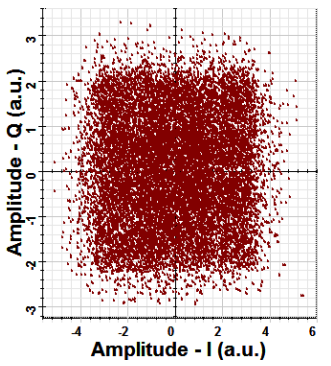

(a)

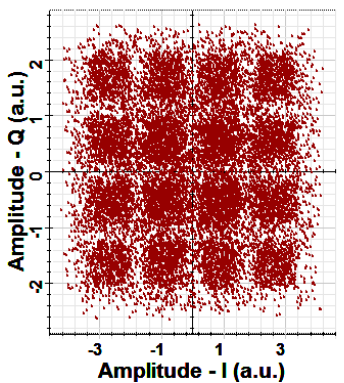

(d)

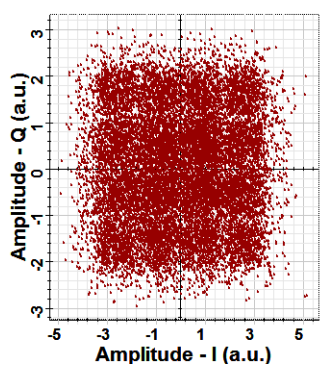

(b)

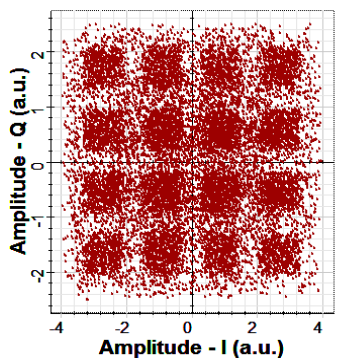

(e)

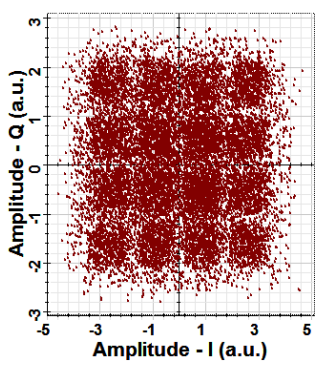

(c)

Figure. 4 Constellation diagrams at the output of the transmitter SRRC Shaping filter for (a) $r=0.0,(b) r=0.1$, (c) $r=0.2$, (d) $r=0.3$, (e) $r=0.4$. The results are reported at $0 \mathrm{~d} \mathrm{Bm}$ transmitted optical power and $1550 \mathrm{~nm}$ wavelength

At the receiver side, a PD with modulation bandwidth equal to the bit rate. Due to the dispersion of the $1 \mathrm{~km}$ fiber link and the linewidth of the laser, the constellations at the outputs of the SRRC matched filters, are rotated by phase angle whose value varies from sub-band to another as shown in Figure 5 which clarifies this phase rotation for the four subbands at $L=1 \mathrm{~km}, \mathrm{r}=0.4, \mathrm{P}_{\mathrm{T}}=0 \mathrm{dBm}$, and $\lambda=1550 \mathrm{~nm}$.

Figure 6 summarizes the RF power spectral density of CAP-16 and the detected 16 symbols in the constellation at the output of decision device which are the same asthose 16 symbols in the constellation at the output of the PAM mapper in the transmitter at $0 \mathrm{dBm}$ transmitting power.

The comparison between the BER of $112 \mathrm{~Gb} / \mathrm{s}$ four-band HMB CAP/QAM with that of single- band for each value of $r$ is performed. It is found that improvement in the BER performance of $112 \mathrm{~Gb} / \mathrm{s}$ single band and multiband is achieved by increasing $r$. That means by making a wider-bandwidth RF CAP signal will decrease the interference between I and $Q$ channels. The BER of $112 \mathrm{~Gb} / \mathrm{s}$ single-band CAP-16 versus CW 
Majidah H. Majeed and Raad S. Fyath; Performance Investigation of $112 \mathrm{~Gb} / \mathrm{s}$ Hybrid Multiband CAP/QAM Schemes for Short Reach Optical Communication Systems, Transactions on Networks and Communications, Volume 4 No. 6, December (2016); pp: 10-32

laser transmitted power at $1550 \mathrm{~nm}$ wavelength is illustrated in Figure 7. At $10^{-3} \mathrm{BER}$, the power improvement obtained with $r=0.4$ is $1.88 \mathrm{dBm}$ over the case of $r=0.0$. The BER performance of $112 \mathrm{~Gb} / \mathrm{s}$ hybrid 4- subband system is shown in Figure 7, and the improvement is of $0.75 \mathrm{dBm}$.

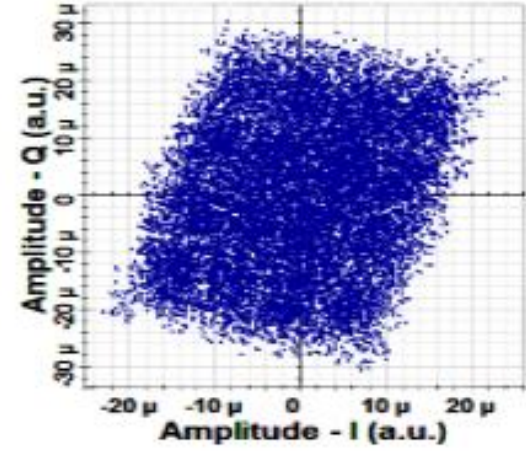

a

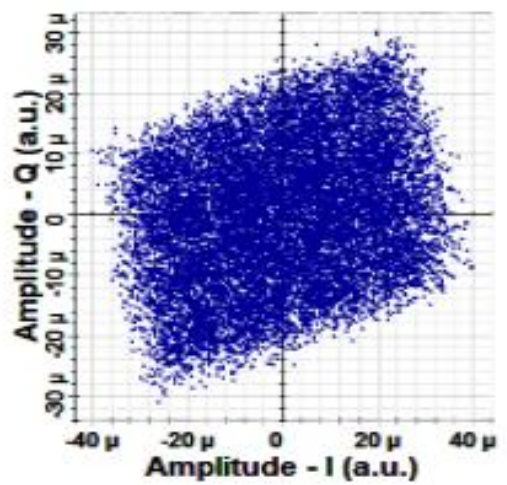

C

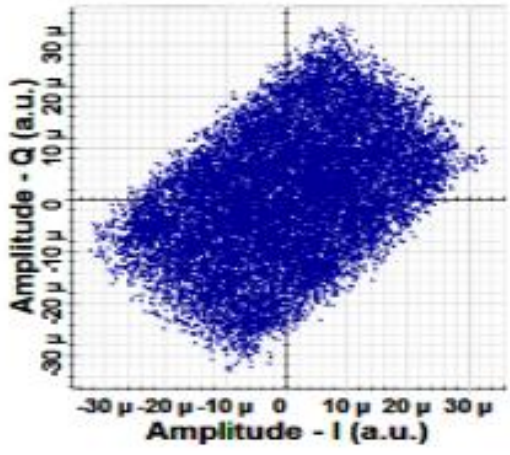

b.

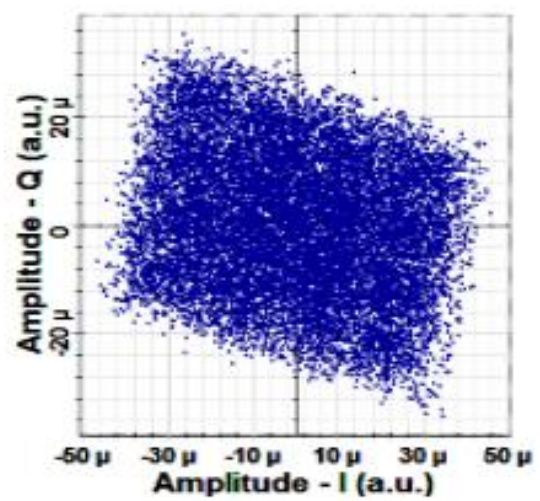

d

Figure. 5 Constellation diagrams at the output of matched filter of each subband along transmission distance $\mathrm{L}=1 \mathrm{~km}, \mathrm{r}=0.4, \mathrm{P}_{\mathrm{T}}=0 \mathrm{dBm}$, and $\lambda=1550 \mathrm{~nm}$ (a) $1^{\text {st }}$ subband,(b) $2^{\text {nd }}$ subband, (c) $3^{\text {rd }}$ subband, (d) $4^{\text {th }}$ subband.

The corresponding curves of CAP-16/QAM-16 operating with $1310 \mathrm{~nm}$ CW laser are given in Figure 8 for $112 \mathrm{~Gb} / \mathrm{s}$ single-band and for multiband systems. Note that the performance improvement are corresponding to $1.75 \mathrm{dBm}$ for the first and approximately zero $\mathrm{dBm}$ for the second.

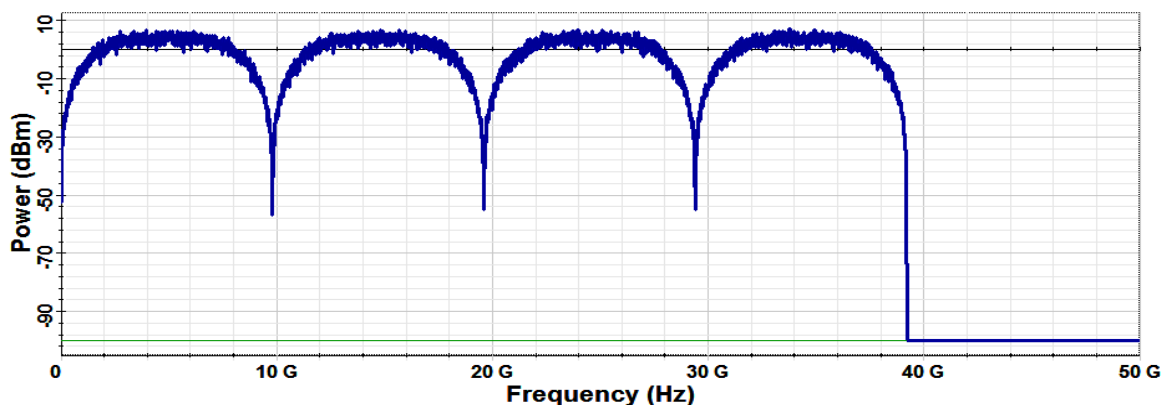

(a) 


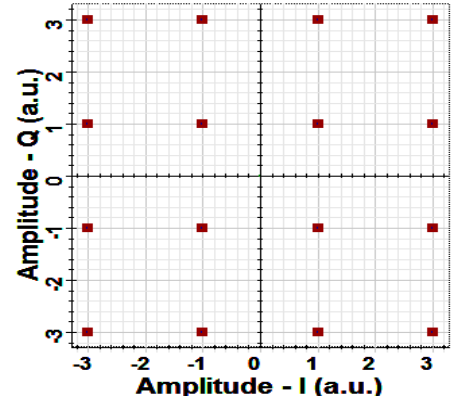

(b)

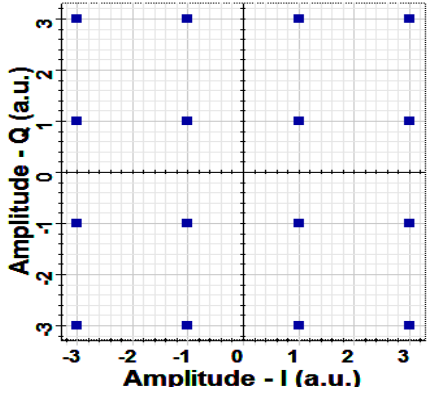

(c)

Figure. 6 (a) RF power spectral density of CAP-16. Signal constellation diagrams at the output of (b) PAM mapper (c) Decision device. $\mathrm{L}=1 \mathrm{~km}, \mathrm{P}_{\mathrm{T}}=0 \mathrm{dBm}$, and $\lambda=1550 \mathrm{~nm}$.

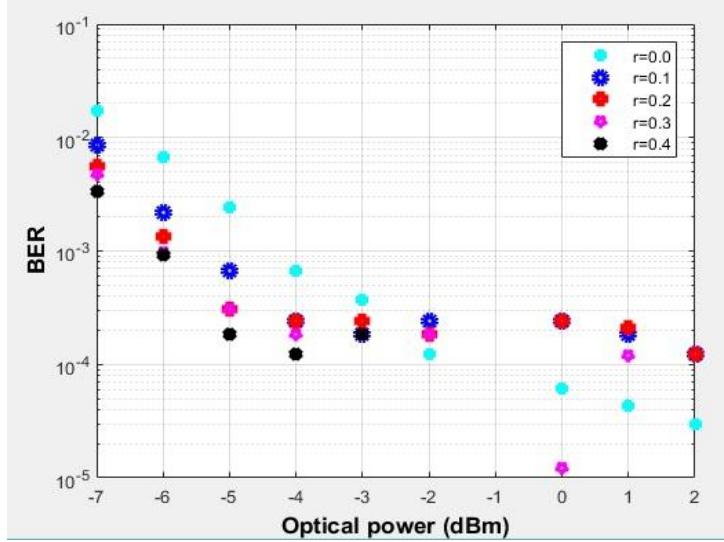

(a)

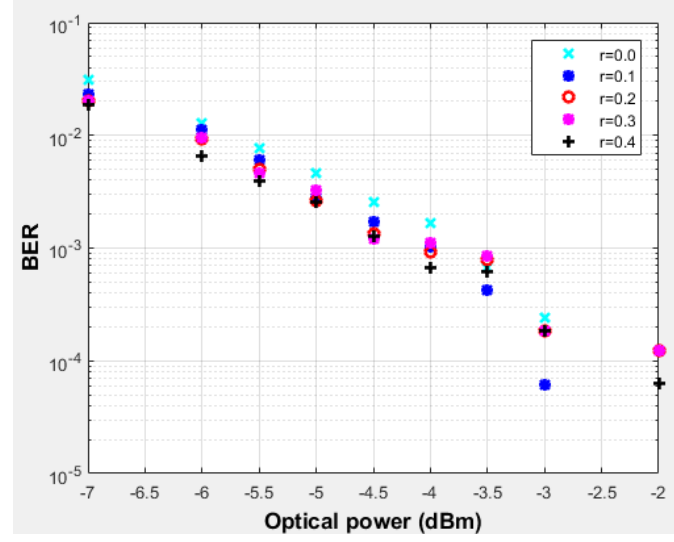

(b)

Figure. 7 Performance of hybrid CAP-16/QAM-16 versus optical power for different values of $r$ at $1550 \mathrm{~nm}$ wavelength. (a) Single-band system (b) 4-subband- system

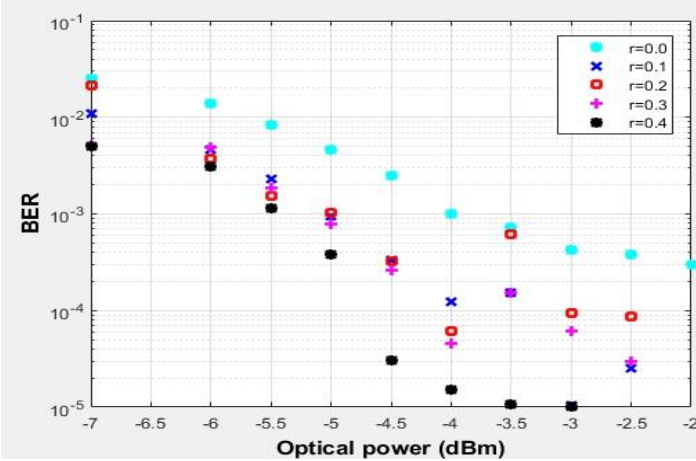

(a)

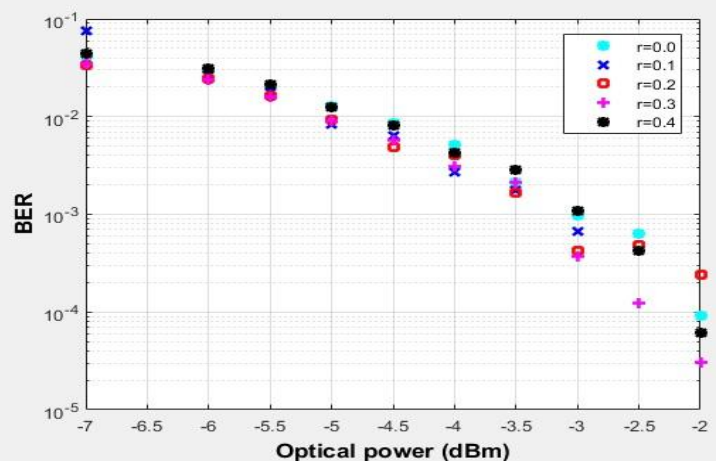

(b)

Figure. 8 Performance of hybrid CAP-16/QAM-16 versus optical power for different values of $\mathrm{r}$ at $1310 \mathrm{~nm}$ wavelength. (a) Single-band system (b) 4-subband system 


\subsubsection{CAP-32/QAM-32}

There is some difference in the implementation of CAP-32, where single QAM sequence generator with differential coding, instead of two gray code PAM sequence generators, is used at the transmitter. Figure 9 illustrates the signal constellation diagrams at different points of CAP-32/QAM-32 system operating with and $\mathrm{PT}=0 \mathrm{dBm}, \mathrm{L}=1 \mathrm{~km}$, and $\lambda=1550 \mathrm{~nm}$

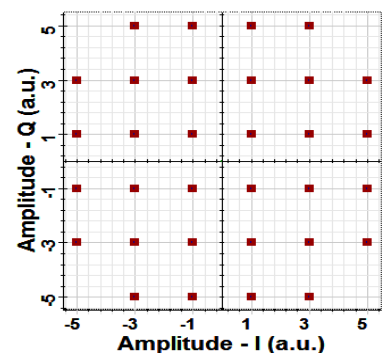

(a)

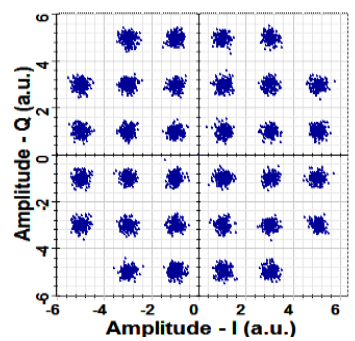

(d)

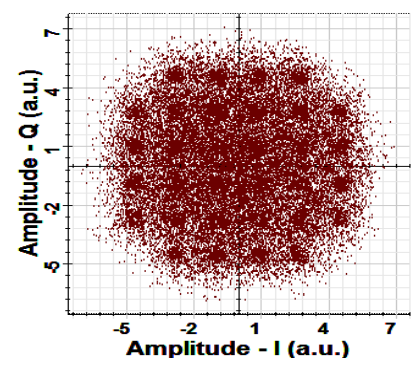

(b)

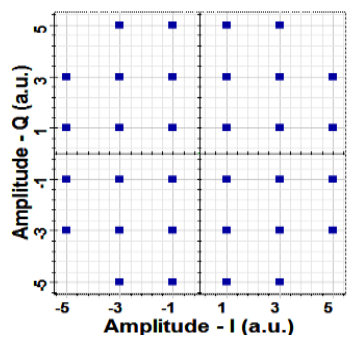

(e)

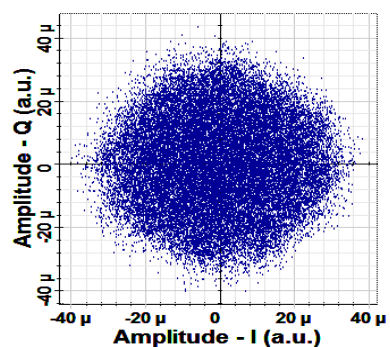

(c)

Figure. 9 Signal constellation diagrams of CAP-32/QAM-32 at the output of(a) QAM mapper, (b) SRRC shaping filters, (c) SRRC matched filters, (d) DSP after off-line processing, (e) Decision device after optimum decision. $\mathrm{L}=1 \mathrm{~km}, \mathrm{PT}_{\mathrm{T}}=0 \mathrm{dBm}$, and $\lambda=1550 \mathrm{~nm}$.

The RF power spectral density of CAP-32 at $\mathrm{P}_{\mathrm{T}}=0 \mathrm{dBm}$ and the eye diagrams at different points of the transceiver for two lengths of the sequence of data are shown in Figure 10

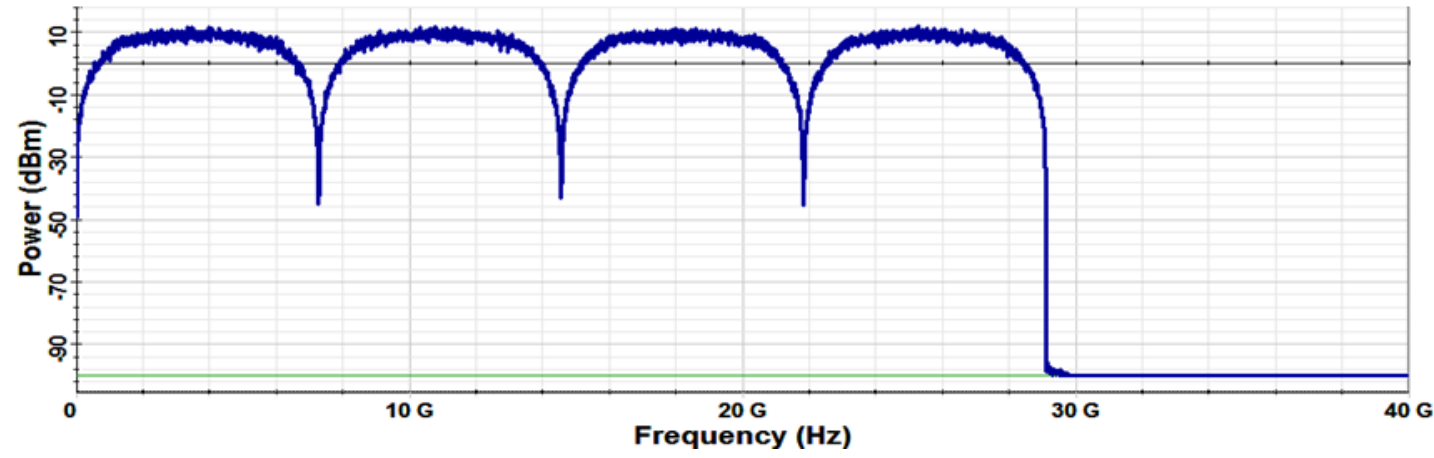

(a) 

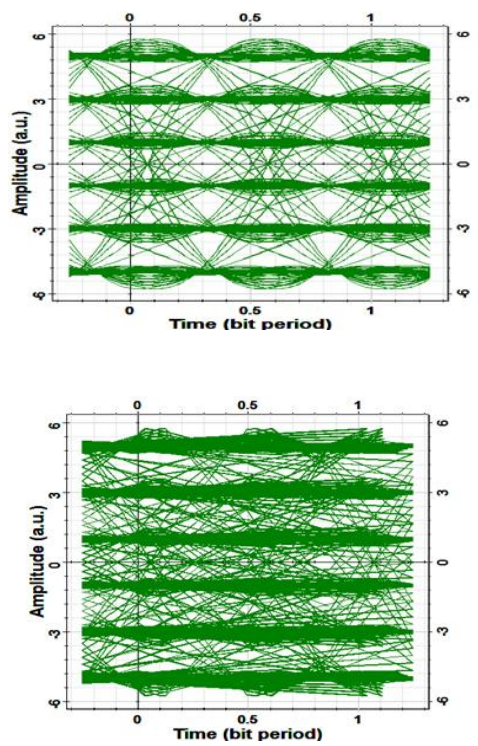

(b)
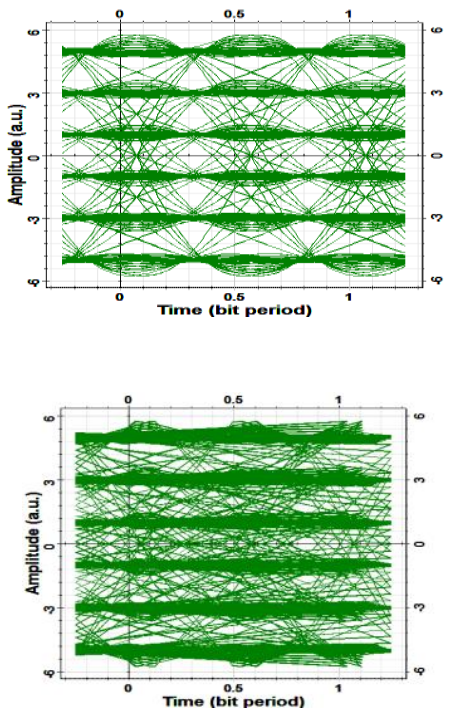

(c)

Figure. 10 (a) RF power spectral density of CAP-32 at PT $=0 \mathrm{dBm}$, and $\lambda=1550 \mathrm{~nm}$. Eye diagram at the output of SRRC shaping filters and matched filters, respectively at PT $=0 \mathrm{dBm}$, and $\lambda=1550 \mathrm{~nm}$ (b) sequence of 2048 bit, (c) sequence 32768 bits

Figures 11 and 12 demonstrate the effect of $r$ on BER of $112 \mathrm{~Gb} / \mathrm{s}$ single-band and multiband CAP32/QAM-32 system with two wavelengths 1550 and $1310 \mathrm{~nm}$, respectively. The power improvement for each case is listed in Table 3, where it is found that single-band and multiband CAP-32 systems operating at $1310 \mathrm{nmis}$ have higherimprovement than that of corresponding systems operating at $1550 \mathrm{~nm}$. This is due to the negligible fiber link dispersion at the $1310 \mathrm{~nm}$ wavelength. The performance of CAP-16/QAM16 and CAP-32/QAM-32 systems are also compared after transmission distance $3 \mathrm{~km}$ with that of B2B transmission. The obtained simulation results for 1550 and $1310 \mathrm{~nm}$ systems are summarized in Figures 13 and 14 , respectively.

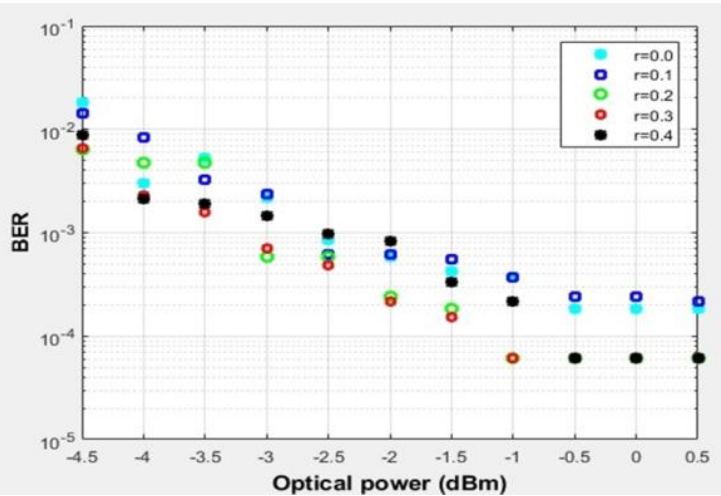

(a)

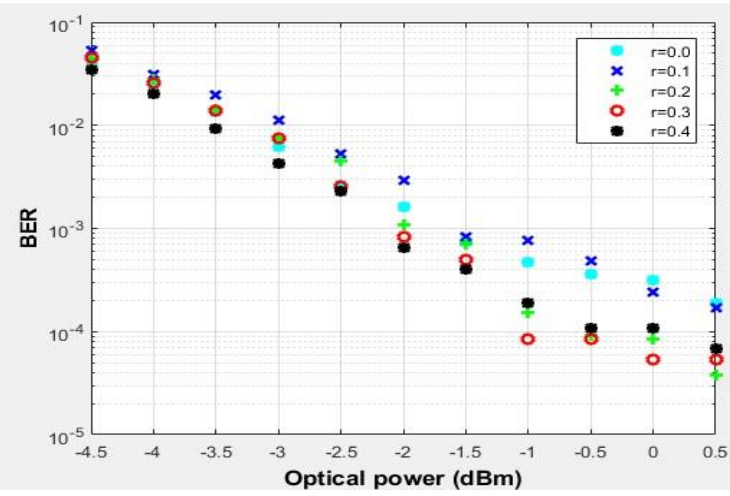

(b)

Figure. 11 Variation the BER of CAP-32 with the optical power for different values of $r$ at $L=k m$ and $\lambda=1550 \mathrm{~nm}$. (a) Single-band system (b) Four-subband system. 


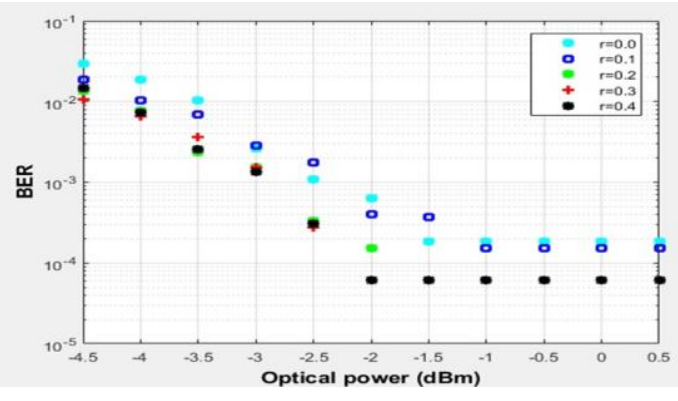

(a)

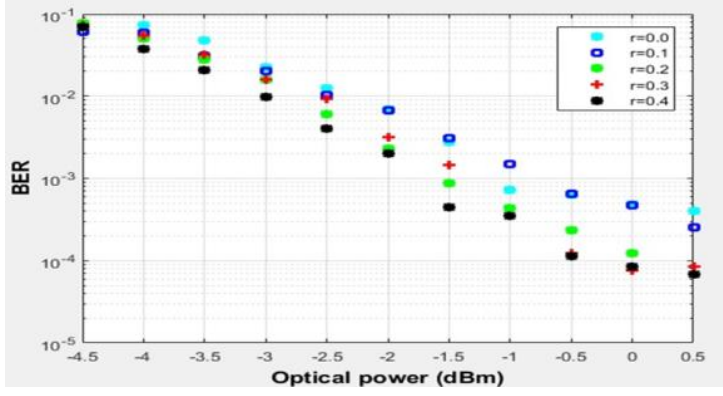

(b)

Figure. 12 Variation the BER of CAP-32 with the optical power for different values of $\mathrm{r}$ at $\mathrm{L}=\mathrm{km}$ and $\lambda=1310 \mathrm{~nm}$. (a) Single-band system (b) Four-subband system

Table 3. Performance improvement at BER of $10^{-3}$ for CAP/QAM schemes.

\begin{tabular}{|c|c|c|}
\hline Scheme & Number of bands & Performance Improvement(dBm) \\
\hline \multirow{3}{*}{ CAP-16/QAM-16 } & Single & $1.88 @ 1550 \mathrm{~nm}$ \\
\cline { 2 - 3 } & Four & $0.75 @ 1550 \mathrm{~nm}$ \\
\cline { 2 - 3 } & Single & $1.75 @ 1310 \mathrm{~nm}$ \\
\cline { 2 - 3 } & Four & $0 \quad$ @ $1310 \mathrm{~nm}$ \\
\hline \multirow{3}{*}{ CAP-32/QAM-32 } & Single & 0 @ $1550 \mathrm{~nm}$ \\
\cline { 2 - 3 } & Four & $0.5 @ 1550 \mathrm{~nm}$ \\
\cline { 2 - 3 } & Single & $0.45 @ 1310 \mathrm{~nm}$ \\
\cline { 2 - 3 } & Four & $0.675 @ 1310 \mathrm{~nm}$ \\
\hline
\end{tabular}

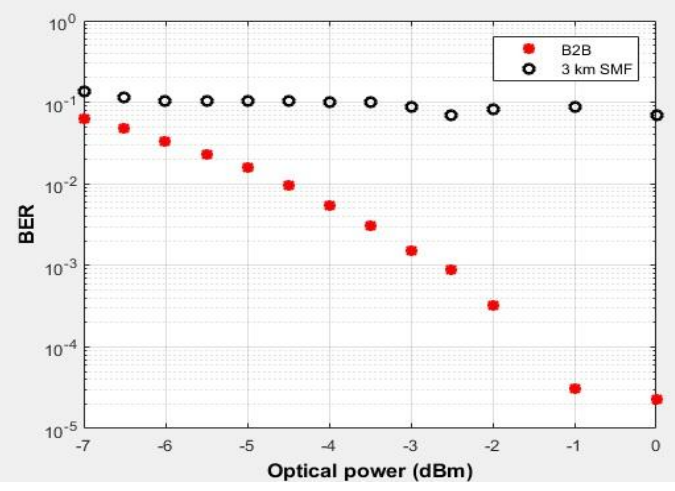

(a)

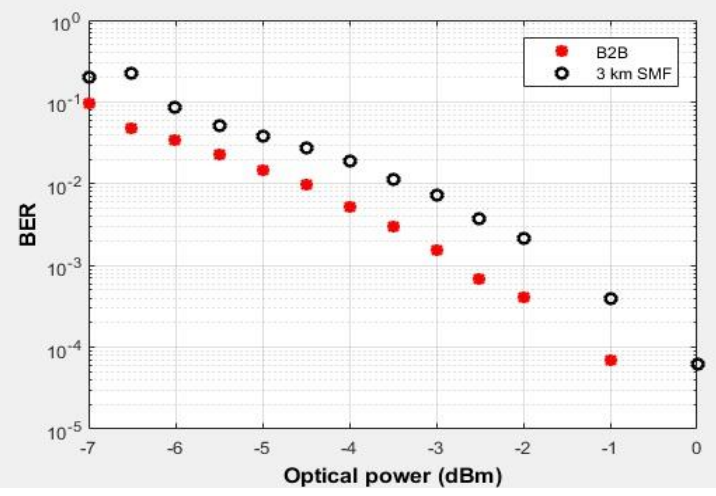

(b)

Figure. 13 BER of multiband CAP-16 system as a function of transmitted laser power after $3 \mathrm{~km}$ transmission distance. Results related to B2B transmission are also given for comparison purposes.(a) 1550 $\mathrm{nm}$ wavelength (b) $1310 \mathrm{~nm}$ wavelength 


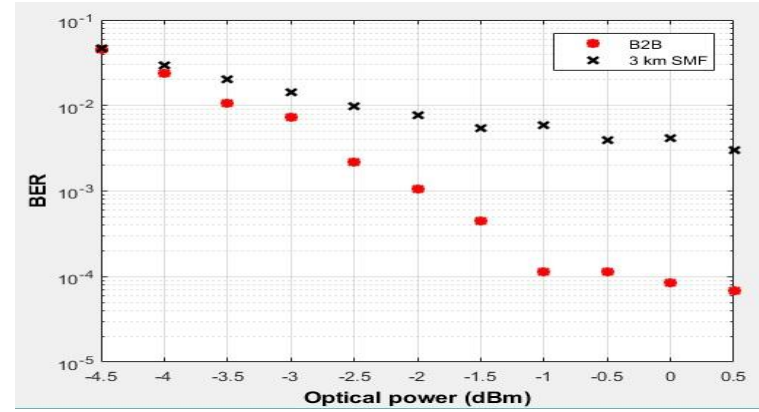

(a)

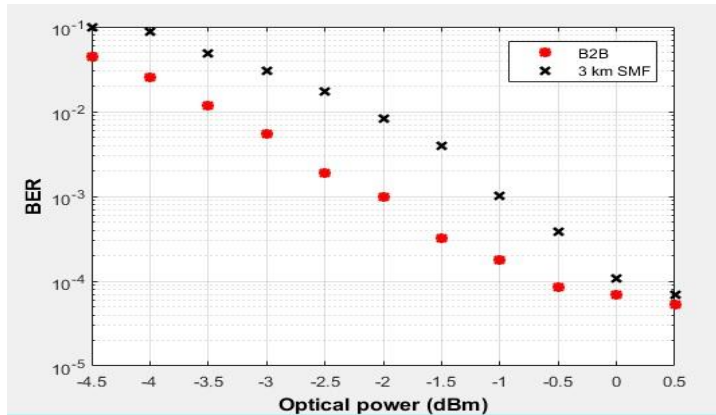

(b)

Figure. 14 BER of hybrid multiband CAP-32/QAM-32 as a function of transmitted laser power after $3 \mathrm{~km}$ transmission distance. Results related to B2B transmission are also given for comparison purposes at (a) 1550 $\mathrm{nm}$ wavelength (b) $1310 \mathrm{~nm}$ wavelength

The operation of the system at $1310 \mathrm{~nm}$ wavelength indicates that the power penalty is limited approximately to $1.2 \mathrm{dBm}$ for CAP-16/QAM-16 and $1 \mathrm{dBm}$ for CAP-32/QAM-32. While that of the 1550 $\mathrm{nm}$ wavelength-case is different; with increasing the transmitted power, the BER is approximately fixed at $\llbracket 10 \rrbracket \wedge(-1)$ for CAP-16/QAM-16 and at $\square 10 \rrbracket \wedge(-2)$ for CAP-32/QAM-32 is fixed. This can be explained by noting that the symbol rate of CAP-32 scheme is lower than that of CAP-16. This means that the electronics and optics components will operate at lower frequency, then the possibility of error will be less. Furthermore, the eye width, which equals to the ratio of time an eye occupies to symbol time period [5] will be larger for CAP-32 system.

\subsubsection{CAP-64/QAM-64}

The signal constellation at different points at the trasceiver of the of CAP-64/QAM-64 scheme are as illustrated in Figure 15 while the RF power spectral density and the eye diagrams of the scheme are given in Figure 16.

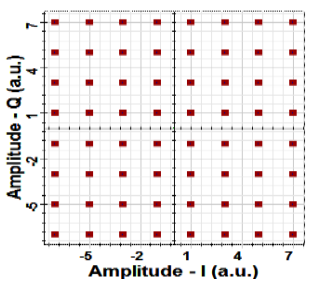

(a)

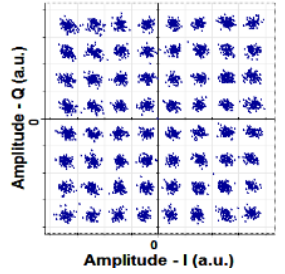

(d)

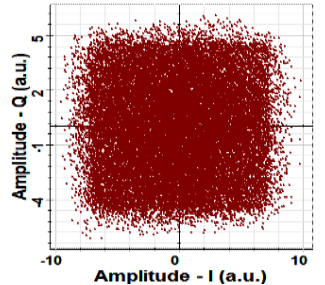

(b)

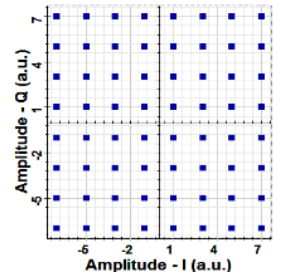

(e)

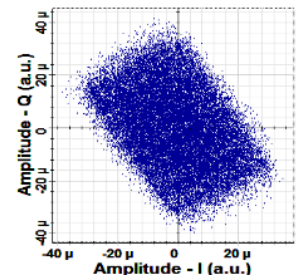

(c)

Figure. 15 Signal constellation diagrams of CAP-64 scheme at the output of the (a) PAM mapper (b) SRRC shaping filters (c) SRRC matched filters (d) DSP package after off-line processing (e)Optimum decision device. $\mathrm{L}=1 \mathrm{~km}, \mathrm{PT}=0 \mathrm{dBm}$ and $\lambda=1550 \mathrm{~nm}$. 
Majidah H. Majeed and Raad S. Fyath; Performance Investigation of $112 \mathrm{~Gb} / \mathrm{s}$ Hybrid Multiband CAP/QAM Schemes for Short Reach Optical Communication Systems, Transactions on Networks and Communications, Volume 4 No. 6, December (2016); pp: 10-32

The BER performance of $112 \mathrm{~Gb} / \mathrm{s}$ single-band and 4-subband CAP-64/QAM-64 schemes with the CW laser power operating at 1550 and $1310 \mathrm{~nm}$ wavelengths is shown in Figures 17 and 18, respectively. Note the BER of the system is not as that of CAP-16/QAM-16 and CAP-32/QAM-32 schemes. For 4-subband system operating at at $\lambda=1550$ and $1310 \mathrm{~nm}$, the BER at $r=0.4$ is approximately the lowest. While for single-band scheme, the lowest curve with $1310 \mathrm{~nm}$ wavelength is at $r=0.4$ and at $r=0.1$ for $1550 \mathrm{~nm}$.

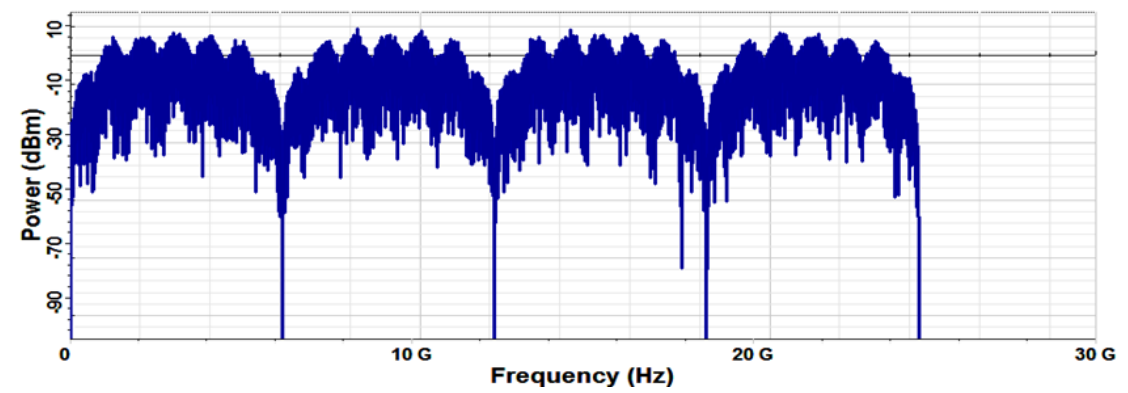

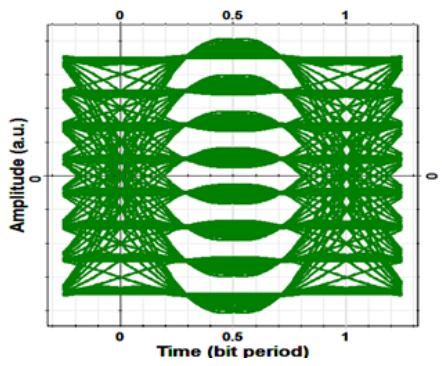

(b)

(a)

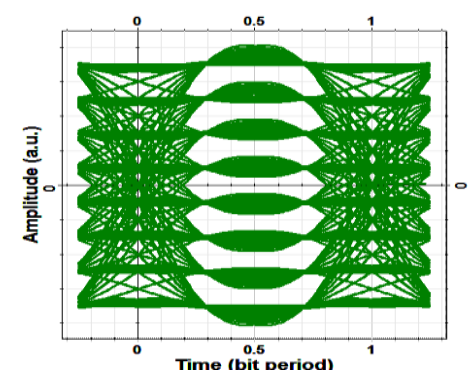

(c)

Figure. 16 (a) RF power spectral density of CAP64/QAM-64scheme.Eye diagram of CAP-64/QAM64schemeatthe output of(b) SRRC shaping filters, (c) Decision device. $L=1 \mathrm{~km}, \mathrm{PT}=0 \mathrm{dBm}$ and $\lambda=1550 \mathrm{~nm}$

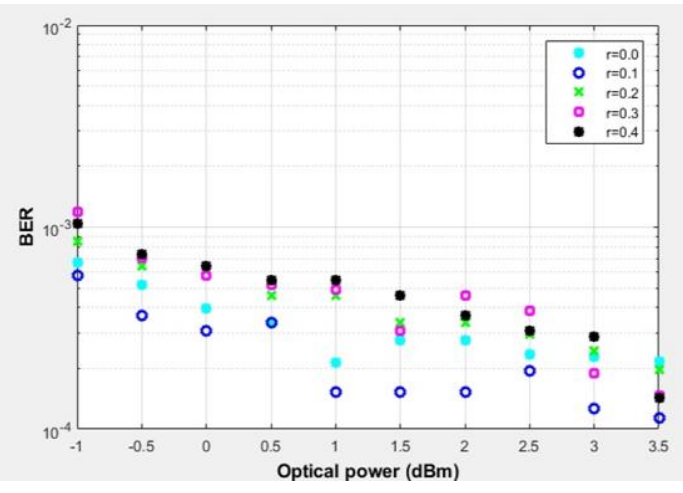

(a)

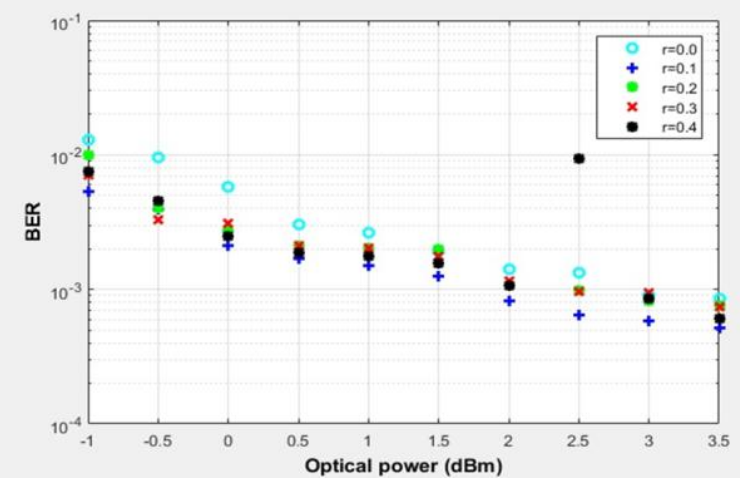

(b)

Figure. 17 Variation the BER of CAP-64/QAM-64 system with the optical power at L=1 $\mathrm{km}$ and $\lambda=1550 \mathrm{~nm}$.

(a) Single-band system (b) Four-subband system. 


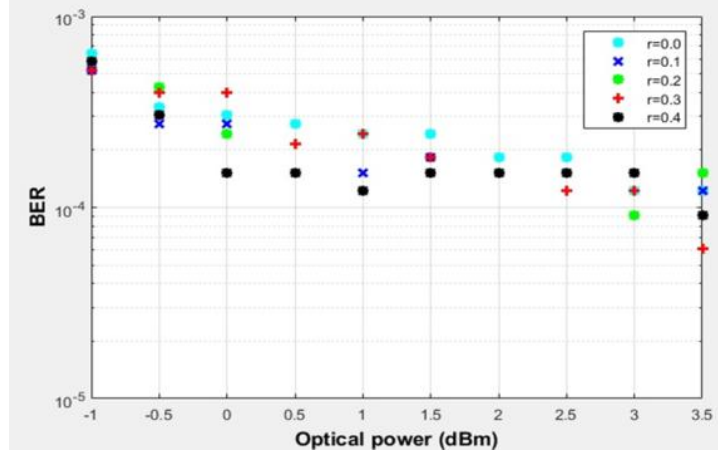

(a)

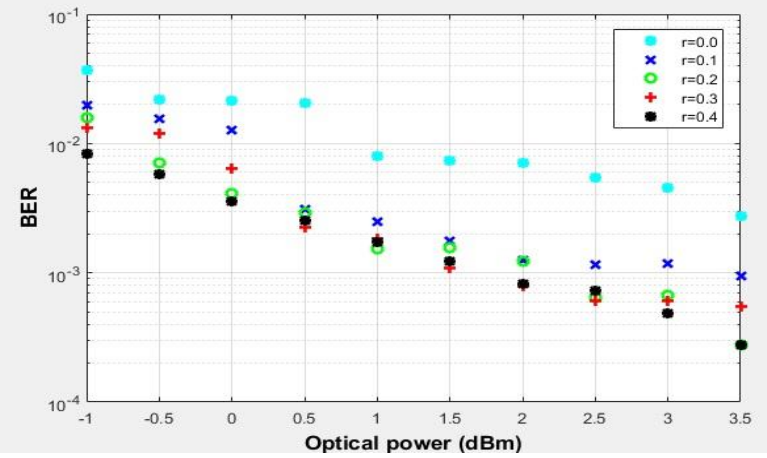

(b)

Figure. 18 BER performance of CAP-64/QAM-64 system as afunction of the optical laser power operating at $L=1 \mathrm{~km}$ and $\lambda=1310 \mathrm{~nm}$. (a) Single-band system (b) Four-subband sy

\subsection{Effect of Number of Subbands}

The investigation of $112 \mathrm{~Gb} / \mathrm{s}$ hybrid 8-subband and 16-subband CAP/QAM systems is also simulated. Although the number of the electronic and the optical components increases, the ability to operate each subband at lower frequency is achieved. The RF power spectral density of CAP-16 is divided into 8 subbands and 16 subbands as given in Figure19. Figures 20and 21 illustrate the signal constellation diagrams at different points in the transceiver of 8-subband and 16-subband CAP-16/QAM-16 systems, respectively. The eye diagrams at the transmitter and the receiver for both 8-subband and 16-subband systems are summarized in Figure 22.

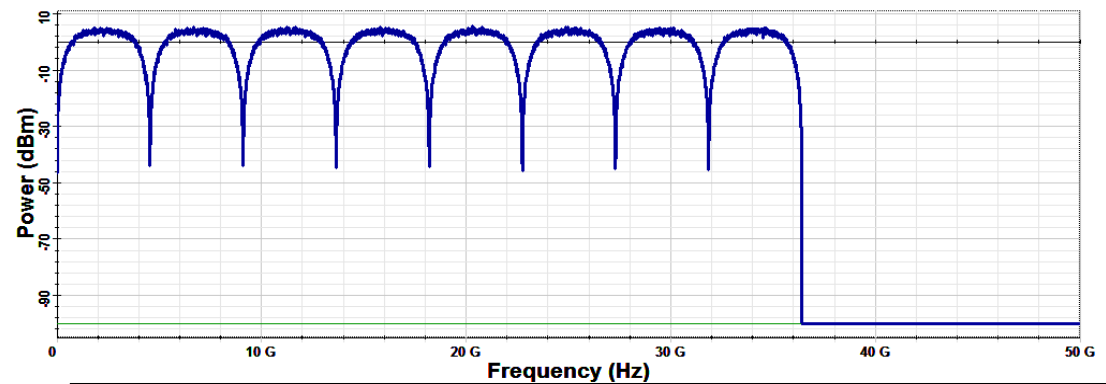

(a)

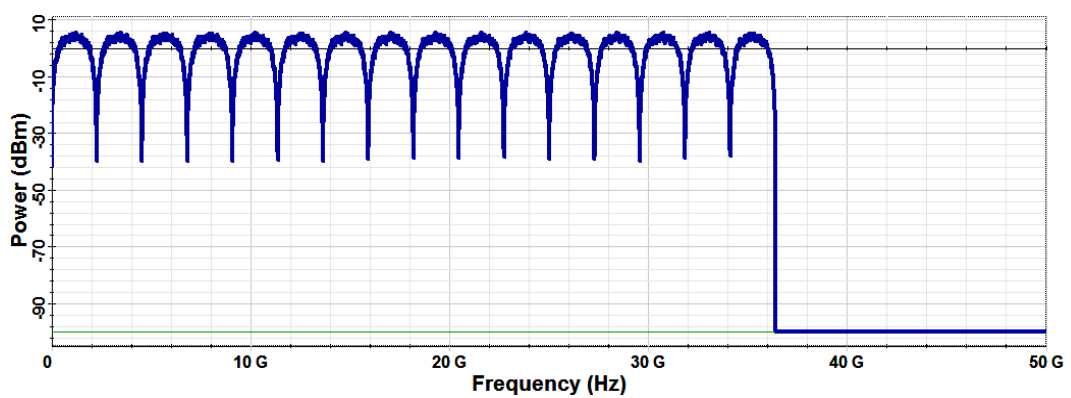

(b)

Figure. 19 RF Power spectral density for $L=1 \mathrm{~km}, \mathrm{PT}=0 \mathrm{dBm}$ and $\lambda=1550 \mathrm{~nm}$. (a) 8 -subband system (b) 16subband system. 


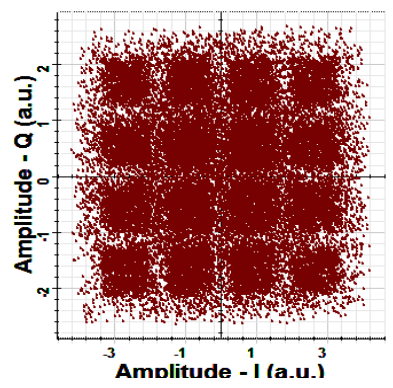

(a)

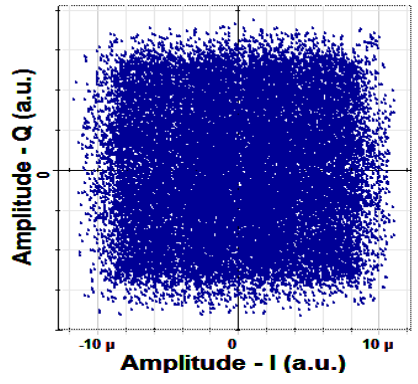

(b)

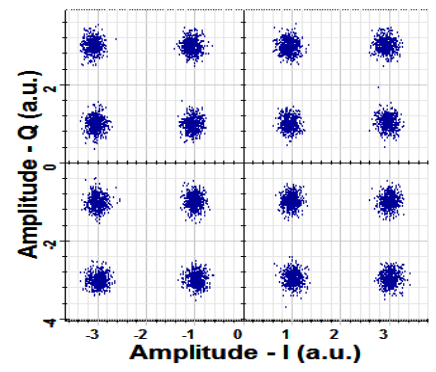

(c)

Figure. 20 Constellation diagrams of 8-subband system at the output of the (a) SRRC shaping filter, (b) SRRC matched filter, (c) DSP package. L= $1 \mathrm{~km}, \mathrm{PT}=0 \mathrm{dBm}$ and $\lambda=1550 \mathrm{~nm}$

The effect of the number of subbands on the performance of the system is also investigated. Figure 23 clarifies the comparison of the BER as a function of transmitted laser power for $112 \mathrm{~Gb} / \mathrm{s}$ hybrid 4subband, 8-subband and 16-subband CAP-16/QAM-16 systems at r equals to 0.3. Note that the curve of 8-subband and 16-subband are closer to each other and the BER is higher than that of 4-subband system

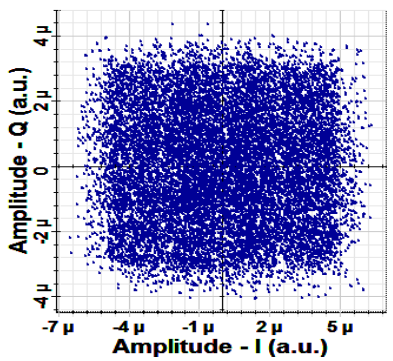

(a)

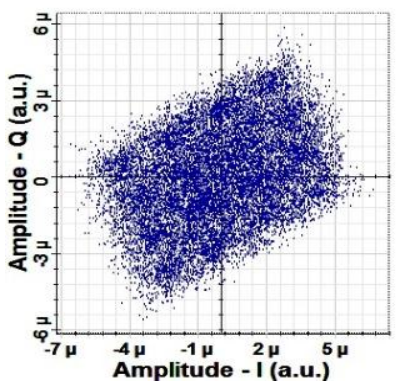

(c)

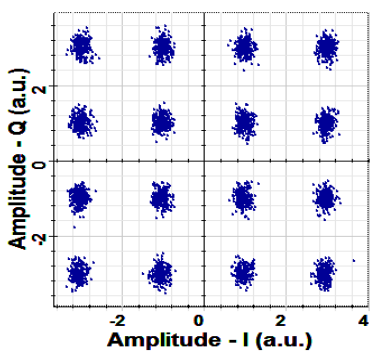

(b)

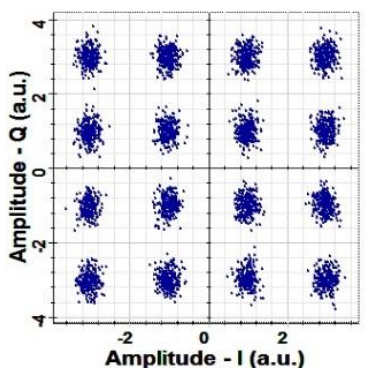

(d)

Figure. 21 Constellation diagrams at the output of (a) SRRC matched filter of 1st subband (b) DSP of 1st subband (c) SRRC matched filter of 16th subband(c) DSP of 16th subband. L= $1 \mathrm{~km}, \mathrm{PT}=0 \mathrm{dBm}$ and $\lambda=1550 \mathrm{~nm}$. 


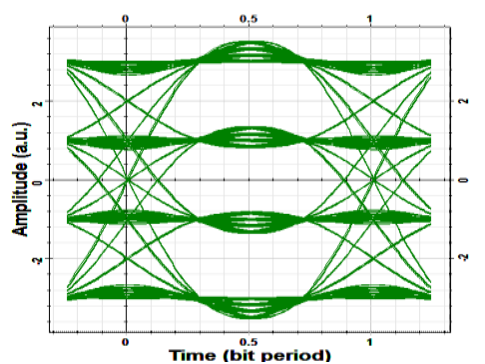

(a)

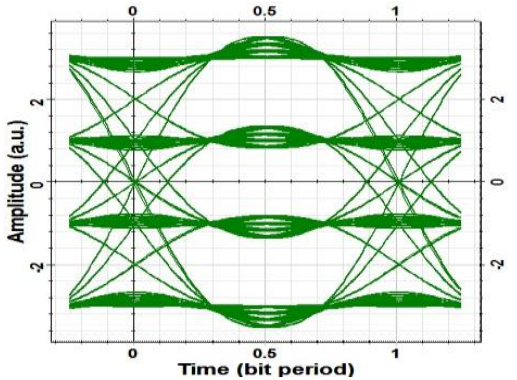

(c)

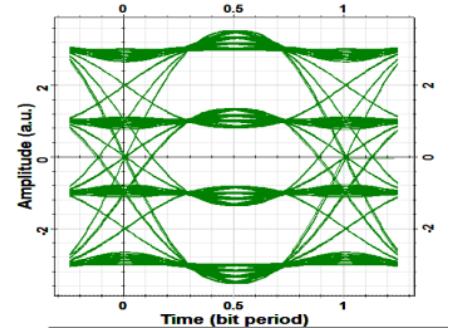

(b)

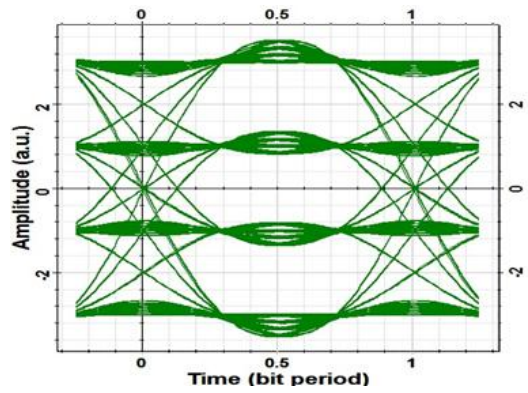

(d)

Figure. 22 Eye diagrams at the output of (a) SRRC shaping filter of the 8-subband system (b) decision device of the 8-subband system (c) SRRC shaping filter of the 16-subband system (d) decision device of the 16-subband. $L=1 \mathrm{~km}, \mathrm{PT}=0 \mathrm{dBm}$, and $\lambda=1550 \mathrm{~nm}$.

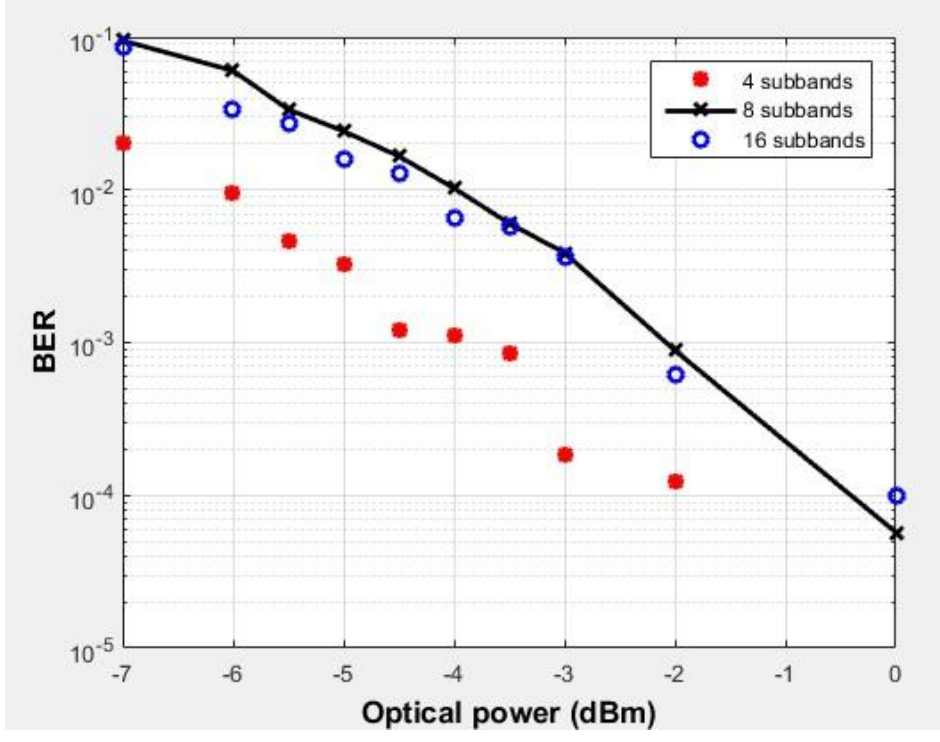

Figure. 23 Effect of number of subbands on the performance the CAP-16/QAM-16 system operating with $\mathrm{L}=1 \mathrm{~km}, \mathrm{P}_{\mathrm{T}}=0 \mathrm{dBm}$, and $\lambda=1550 \mathrm{~nm}$.

\subsection{Maximum Allowable Distance}

\subsubsection{Effect of Operating Wavelength}

The maximum allowable transmission distance for a maximum BER of $\llbracket 10 \rrbracket \wedge(-3)$ is deduced for CAP16/QAM-16 system at $0 \mathrm{dBm}$ CW laser optical power and for two operating wavelengths $1550 \mathrm{~nm}$ and $1310 \mathrm{~nm}$. The maximum allowable distance is approximately directly proportional to the transmitted CW laser power measured in decibels for both wavelengths as shown in Figure 24. The calculated slopes are 
Majidah H. Majeed and Raad S. Fyath; Performance Investigation of $112 \mathrm{~Gb} / \mathrm{s}$ Hybrid Multiband CAP/QAM Schemes for Short Reach Optical Communication Systems, Transactions on Networks and Communications, Volume 4 No. 6, December (2016); pp: 10-32

$0.2 \mathrm{~km} / \mathrm{dBm}$ for $1550 \mathrm{~nm}$ wavelength (the fiber attenuation=0.2 dB/km) and $2 \mathrm{~km} / \mathrm{dBm}$ for $1310 \mathrm{~nm}$ wavelength (fiber attenuation $=0.4 \mathrm{dBm} / \mathrm{km}$ ).

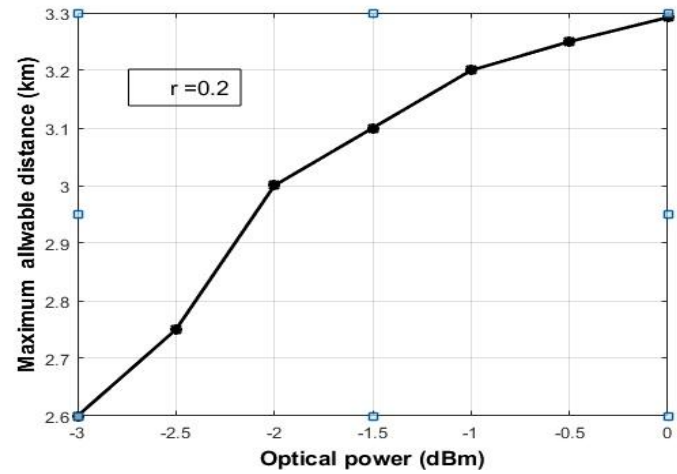

(a)

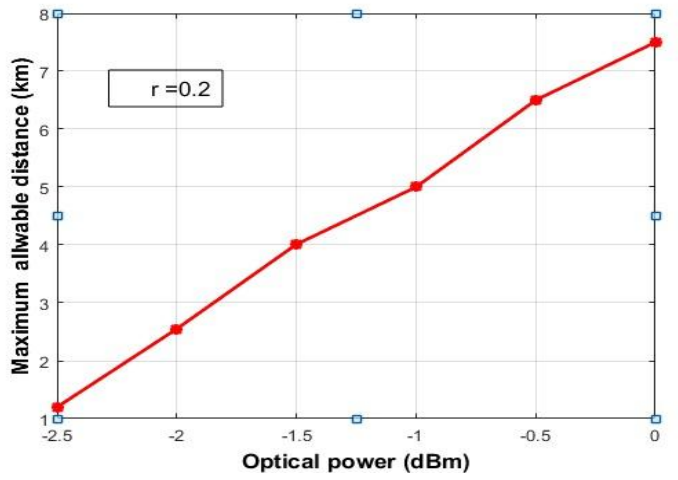

(b)

Figure .24 Maximum allowable distance for $[10 \rrbracket \wedge(-3)$ BER as a function of optical power for CAP$16 /$ QAM-16 system $\quad$ (a) $1550 \mathrm{~nm}$ wavelength (b ) $1310 \mathrm{~nm}$ wavelength

\subsubsection{Effect of Roll-off Factor}

The maximum allowable distance with $112 \mathrm{~Gb} / \mathrm{s}$ 4- subband CAP-16 system is deduced. Assuming $0 \mathrm{dBm}$ transmitting power, the results are summarized in Table 4 for both 1550 and $1310 \mathrm{~nm}$ wavelengths.

Table 4. Maximum allowable distance to achieve a BER of $10^{-3}$ in CAP-16/QAM-16 system at $P_{T}=0 \mathrm{dBm}$.

\begin{tabular}{|c|c|c|}
\hline Roll-off Factor & \multicolumn{3}{|c|}{ Maximum Allowable Distance $(\mathbf{m})$} \\
\hline & $\lambda=1550 \mathbf{n m}$ & $\lambda=1310 \mathbf{n m}$ \\
\hline 0 & 3975 & 7550 \\
\hline 0.1 & 3475 & 7975 \\
\hline 0.2 & 3075 & 7950 \\
\hline 0.3 & 2550 & 8000 \\
\hline 0.4 & 2610 & 7533 \\
\hline
\end{tabular}

The 4-subbands CAP-16/QAM-16 system operating with $1310 \mathrm{~nm}$ wavelength is better than the $1550 \mathrm{~nm}$ counterpart since it offers longer distance with all values of $r$ considered here. This is due to the absence of fiber group velocity dispersion at $1310 \mathrm{~nm}$.

\subsubsection{Effect of Modulation Order}

Table 5 lists the maximum allowable distance corresponding to a BER of $\square 10 \rrbracket \wedge(-3)$ obtained with 112 $\mathrm{Gb} / \mathrm{s}$ 4-subband CAP/QAM scheme. Both $1550 \mathrm{~nm}$ and $1310 \mathrm{~nm}$ wavelength-lasers at $0 \mathrm{dBm}$ transmitted power are used for simulation. Different orders of modulation of CAP/QAM at 0.2 roll-off factor are investigated. For CAP-16 and CAP-32 systems, the distance obtained with $1310 \mathrm{~nm}$ wavelength is approximately twice that with $1550 \mathrm{~nm}$ wavelength. Note that CAP-64 modulation offers shortest distance at both wavelengths. 
Table. 5 Maximum allowable distance for different order of modulation.

\begin{tabular}{|c|c|c|}
\hline Order of modulation & CW laser wavelength $(\mathbf{n m})$ & Max. Allowable Distance $(\mathbf{m})$ \\
\hline CAP-16/QAM-16 & 1310 & 7500 \\
\hline \multirow{2}{*}{ CAP-32/QAM-32 } & 1550 & 3075 \\
\hline \multirow{2}{*}{ CAP-64/QAM-64 } & 1310 & 4500 \\
\hline & 1550 & 2575 \\
\hline & 1310 & 400 \\
\hline
\end{tabular}

The performance of $112 \mathrm{~Gb} / \mathrm{s} \mathrm{HMB}$ and single-band CAP/QAM systems have been investigated. The systems have been implemented using analog root-raised cosine filters and a single laser operating at either 1550 or $1310 \mathrm{~nm}$. The effect of filter roll-off factor $r$, number of subbands, and modulation order have been addressed. It has been found that the BER performance is enhanced by increasing $r$. At BER performance of $\llbracket 10 \Omega \wedge(-3)$, the power performance of 4 -subband and single-band CAP-16/ QAM-16 systems is improved by 0.75 and $1.88 \mathrm{~dB}$, respectively, at $1550 \mathrm{~nm}$ wavelength when $r$ increases from 0 to 0.4. These values are to be compared with 0.5 and $0.45 \mathrm{~dB}$, respectively, for CAP-32/ QAM-32 system

\section{ACKNOWLEDGMENT}

One of the authors, Mrs. Majeed wants to thank the College of Engineering at University of Diyala, Iraq, for offering her the Ph.D scholarship.

\section{REFERNCES}

[1] Wei. J., Cunngham. D., Penty. R., White. I., Study of 100 Gigabit Ethernet Using Carrierless Amplitude/Phase Modulation and Optical OFDM, Journal of Lightwave Technology, vol. 31, No. 9, May 2013.

[2] Tau. L., Ji. Y., Liu. J., Lau. A., Chi. N., and Lu. C., Advanced Modulation Formats for Short Reach Optical Communication Systems, IEEE Network, pp. 6-13, Nov./Dec. 2013.

[3] Tao. L., Wang. Y., Gao, Y., Lau. A., Chi. N., and Lu. C., Experimental Demonstration of $10 \mathrm{~Gb} / \mathrm{s}$ Multilevel Carrierless Amplitude/Phase Modulation for Short Reach Optical Communication System, Optics Express, Vol. 21, No.5, pp. 6459-6465, 2013.

[4] Olmedo. M., Zuo. T., Jensen. J., Zhong. Q., Xu. X., Monroy. I., Multiband Carrierless Amplitude Phase Modulation for High Capacity Optical Data Links, J. Lightwave Technology, vol. 32, no, 4, pp. 798-804, Feb. 2014.

[5] Wei. J., David. Q., Cunningham. G., Penty. R., and White. I., 100- Gb/s Hybrid Multiband CAP/QAM Signal Transmission Over a Single Wavelength, Journal of Lightwave Technology, vol. 33, No. 2, pp. 415-423, Jan. 2015. 
Majidah H. Majeed and Raad S. Fyath; Performance Investigation of 112 Gb/s Hybrid Multiband CAP/QAM Schemes

for Short Reach Optical Communication Systems, Transactions on Networks and Communications, Volume 4 No.

6, December (2016); pp: 10-32

[6] Othman. M. B., High Dimensional Modulation and MIMO Techniques for Access Networks, PhD Thesis, Department of Photonics Engineering, DTU Fotonik, Oct. 2012.

[7] Ray Liu. K. J., Digital Signal Processing for Multimedia Systems, University of Maryland, Japan 1999.

[8] Ziemer. P. E., Trander. W. H., Principles of Communications Systems, Modulation, and Noise, 7th edition, Wiley, USA 2014.

[9] Cubukce. E, Root Raised Cosine (RRC) Filters and Pulse Shaping in Communication Systems, 2012. https://ntrs.nasa.gov/archive/nasa/casi.ntrs.nasa.gov/20120008631.pdf

[10] Inter Symbol Interference (ISI) and Root- raised Cosine (RRC) Filtering, www.complexreal.com

[11] Abdolhamid. A. and Jhons. D., A comparison of CAP/QAM Architectures, IEEE International Symposium on Circuits and Systems, 1998. 